\title{
Design Patterns for Sociality in Human-Robot Interaction
}

\author{
Peter H. Kahn, Jr. ${ }^{1}$, Nathan G. Freier ${ }^{2}$, Takayuki Kanda ${ }^{3,}$ Hiroshi Ishiguro ${ }^{3,4}$, Jolina H. Ruckert ${ }^{1}$, \\ Rachel L. Severson ${ }^{1}$, \& Shaun K. Kane ${ }^{5}$. \\ ${ }^{1}$ Department of Psychology \\ University of Washington \\ Seattle, Washington, USA \\ pkahn@u.washington.edu \\ jhr333@u.washington.edu \\ raches@u.washington.edu \\ ${ }^{4}$ Department of Adaptive Systems \\ Osaka University \\ Osaka, Japan \\ ishiguro@atr.jp \\ ${ }^{2}$ Language, Literature, and \\ Communication \\ Rensselaer Polytechnic Institute \\ Troy, NY, USA \\ freien@rpi.edu \\ ${ }^{3}$ Intelligent Robotics and \\ Communication Laboratory \\ ATR \\ Kyoto, Japan \\ kanda@atr.jp \\ ${ }^{5}$ The Information School \\ University of Washington \\ Seattle, Washington, USA \\ skane@u.washington.edu
}

\begin{abstract}
We propose that Christopher Alexander's idea of design patterns can benefit the emerging field of HRI. We first discuss four features of design patterns that appear particularly useful. For example, a pattern should be specified abstractly enough such that many different instantiations of the pattern can be uniquely realized in the solution to specific problems in context. Then, after describing our method for generating patterns, we offer and describe eight possible design patterns for sociality in human robot interaction: initial introduction, didactic communication, in motion together, personal interests and history, recovering from mistakes, reciprocal turn-taking in game context, physical intimacy, and claiming unfair treatment or wrongful harms. We also discuss the issue of validation of design patterns. If a design pattern program proves successful, it will provide HRI researchers with basic knowledge about human robot interaction, and save time through the reuse of patterns to achieve high levels of sociality.
\end{abstract}

\section{Categories and Subject Descriptors}

H.5.2 [Information Interfaces and Presentation]: User Interfaces - evaluation/methodology, interaction styles, theory and methods, user-centered design.

\section{General Terms}

Design, Human Factors, Theory

\section{Keywords}

Design patterns, sociality, human-robot interaction
Permission to make digital or hard copies of all or part of this work for personal or classroom use is granted without fee provided that copies are not made or distributed for profit or commercial advantage and that copies bear this notice and the full citation on the first page. To copy otherwise, or republish, to post on servers or to redistribute to lists, requires prior specific permission and/or a fee.

HRI'08, March 12-15, 2008, Amsterdam, Netherlands.

Copyright 2008 ACM 978-1-60558-017-3/08/03...\$5.00.

\section{INTRODUCTION}

In recent years, various fields within computer science and human-computer interaction have been drawing on Christopher Alexander's idea of design patterns $[1,2]$. According to Alexander [2], a "pattern describes a problem which occurs over and over again in our environment, and then describes the core of the solution to that problem, in such a way that you can use this solution a million times over, without ever doing it the same way twice" (p. x). Coming out of the field of architecture, Alexander proposed an initial set of 253 patterns. For example, one of his patterns is titled "Light on two sides of every room." He writes: "The importance of this pattern lies partly in the social atmosphere it creates in the room. Rooms lit on two sides, with natural light, create less glare around people and objects" (p. 748). He argues that this "pattern, perhaps more than any other single pattern, determines the success or failure of a room" because "when they have a choice, people will always gravitate to those rooms which have light on two sides, and leave the rooms which are lit only from one side unused and empty" (p. 747).

There is now a burgeoning body of work that extends the idea of design patterns into the fields of ubiquitous computing [10], software engineering $[14,15]$, interaction design $[4-8,12]$, and usability $[9,16,27]$. The reasons for this interest are diverse. For example, Chung et al. [10] write that design patterns "are a format for capturing and sharing design knowledge" and can "aid practice by speeding up the diffusion of new interaction techniques" (p. 233). Salingaros [21] writes that design patterns provide "a way of understanding, and possibly controlling a complex system" and are an important tool "with which to build something that is functionally and structurally coherent" (p. 154).

In this paper, we propose that in similar ways the idea of design patterns can benefit the emerging field of HRI. To develop our position, we introduce in Section 2 the idea of design patterns to those who may be unfamiliar with them, or who may have encountered them only within the context of computer science (where patterns emphasize practical programming representations). In Section 3 we explain our method for generating design patterns. Then in Section 4 we show what HRI design patterns might look like by drawing on our 
collaborative laboratory's research that involves children's and adolescents' social interactions with a humanoid robot. We offer an initial set of eight HRI design patterns for consideration. In Section 5, we discuss the issue of validating design patterns. Finally, we discuss the promise of design patterns for moving the field of HRI forward.

\section{DESIGN PATTERNS: FOUR CENTRAL IDEAS}

Alexander has written three major books on patterns. The Timeless Way of Being provides the theoretical structure to what Alexander views is a universal way of building that, across geography and time, enhances people's sense of wellbeing and aliveness [1]. A Pattern Language provides 253 patterns (within 1171 pages of text and photos) that start with patterns for the higher order organization of towns (e.g., the distribution of towns and identifiable neighborhoods) then to buildings (e.g., south facing outdoors, entrance transition, and courtyards) and then to construction within the buildings (e.g., windows that open wide, front door bench, and pools of light) [2]. And The Oregon Experiment applies design patterns and the larger idea of a pattern language on site at the University of Oregon [3].

Recognizing the decades of work by Alexander and his colleagues, any brief summary of design patterns is necessarily an oversimplification. But, with that said, four central ideas seem to us particularly useful in applying design patterns to HRI.

1. Patterns are specified abstractly enough such that many different instantiations of the pattern can be realized in the solution to a problem. As a point of contrast, imagine the pattern for a shirt that specifies the form, size, material, and color. It is a pattern, but not of the form Alexander is interested in, for though one could create a multitude of shirts from the pattern, the products would all be the same. In contrast, Alexander [1] writes that a design pattern is "a unitary pattern of activity and space, which repeats itself over and over again, in any given place, always appearing each time in a slightly different manifestation" (p. 181). For example, Alexander's pattern mentioned above, "Light on two sides of every room," allows for a multitude of unique concretizations of the pattern that best fit a specific building, specific site, and individual preferences.

2. Patterns can be and often are combined. In this sense, patterns should not ultimately be seen as individual units, but part of a larger organization, what Alexander calls a pattern language. Alexander [2] writes: "[I am presenting] the collection of all 253 patterns as a whole, as a language, within which you can create an infinite variety of combinations" ( $p$. xi). Elsewhere Alexander [1] writes: "both ordinary languages and pattern languages are finite combinatory systems which allow us to create an infinite variety of unique combinations, appropriate to different circumstances, at will" (p. 187). For example, Alexander [2] provides a pattern of the "street café (\#88) which he says should be "intimate places...open to a busy path, where people can sit with coffee or a drink and watch the world go by. Build the front of the café so that a set of tables stretch out of the café, right into the street" (p. 439). Another pattern is "access to water" (\#25): "Always preserve a belt of common land, immediately beside the water. And allow dense settlements to come right down to the water only at infrequent intervals along the water's edge" (p. 137). In an appropriate context, it could work nicely to combine both patterns: say, a promenade along a river or lake with then a café opening to the promenade, but set back just a bit from the water itself. From Alexander's perspective, that would represent one of the infinite ways in which patterns can be combined, and through which an "alive" city can be built.

3. Less complex patterns (from the standpoint of an organizational structure) are often hierarchically integrated into more complex patterns. Alexander [2] writes: "What is most important...[are] the connections between the patterns. Each pattern is connected to certain 'larger' patterns which come above it in the language; and to certain 'smaller' patterns which come below it in the language" (p. xii). For example, Alexander has a pattern called "different chairs" (\#251): "Never furnish any place with chairs that are identically the same. Choose a variety of different chairs, some big, some small, some softer than others, some rockers, some very old, some new, with arms, without arms" (p. 1159). One could then imagine the above café pattern combined with the above access to water pattern, and then different chairs placed within the café; in this way, a lower-level pattern is hierarchically integrated into larger combinatory patterns.

4. Design patterns are fundamentally patterns of human interaction with the physical and social world. Alexander [1] asks "where [do] these patterns come from, and also where [does] the variation comes from"? (p. 181). He answers: "The patterns in our minds are, more or less, mental images of the patterns in the world: they are abstract representations of the very morphological rules which define the patterns in the world" (p. 181). However, Alexander notes a difference that helps explain the variation: "The patterns in the world merely exist. But the same patterns in our minds are dynamic. They have force. They are generative" (p. 182). Recall, too, the above passage where Alexander [1] writes of patterns being of "activity and space" (p. 181). It is in this interactional sense that providing only a coherent account of the structure of the world is not enough. Virtually all science, if not much thought, revolves around patterning or structuring the world - from the chemical pattern of a molecule to the mathematical pattern of a black hole. But the idea of a design pattern has this additional requirement that it characterize the interactional aspect between humans and their physical and social world.

\section{OUR METHOD FOR GENERATING DESIGN PATTERNS FOR SOCIALITY IN HRI}

Alexander [1] writes that "a pattern which lives...allow the forces to run free: and liberate the world from the imprisoning effect of concepts and opinions" (p. 297). "The more living patterns there are in a place...the more it glows, the more it has that self-maintaining fire which is the quality without a name" (p. x). "This quality in buildings and in towns cannot be made, but only generated, indirectly, by the ordinary actions of the people, just as a flower cannot be made, but only generated from the seed" (p. xi). 
Given not only the large corpus of Alexander's work, but that he sought after patterns that would always have this "quality without a name" - a quality that is not so easy to pin down - it is not surprising that people disagree not only on what counts as patterns, but on how to generate them. In our view, and we suspect Alexander's view, many people have codified patternmaking into too rigid a mold. For example, just following the dictum - specify context and then problem, and then generate solution - will not by itself bring forward an alive pattern. No more than the pattern, noted above, that specifies the form, size, material, and color of a shirt can be considered an alive pattern.

All of us - as he writes above, "the ordinary actions of the people" - can generate patterns in Alexander's domain of the built and natural world. We can because we all have a lifetime of interactional experience with the built and natural world. We live in apartments and houses, shop in stores, play in parks, meander along paths, walk in the rain, gaze out windows, drive cars, populate towns and cities, sit on benches, watch leaves fall from trees - the list is very long. But with social robots, the list is very short, almost non-existent. There are very few social robots yet in the world. Thus, even if there were agreement on what counts as the right way to generate an Alexander pattern, HRI methods would necessarily need to deviate from it.

Accordingly, we employed a humanoid robot, ATR's Robovie, in a laboratory setting, and through controlling some of Robovie's speech and action from behind the scenes, we created social situations that children and adolescents could engage in. Various forms of such a "Wizard-of-Oz" (WoZ) technique for controlling aspects of a robot have been used successfully by others (cf., Robbins, Dautenhahn, Boekhorst, \& Billard [20]; Green, Huttenrauch, \& Eklundh, [17]; de Ruyter, Saini, Markopoulos, \& van Breemen [11]). Our goal, eventually, was to sequence a compelling array of social situations between children and Robovie such that children would, within a 15 minute period, come to view Robovie, potentially, as a social other. At that junction, we would be positioned for an experiment (data analysis is currently in progress) that investigates whether children grant humanoid robots intrinsic moral value and moral standing.

Even given our WoZ techniques, our design patterns were limited by the capabilities we could implement through the robot itself. In terms of its specifications, our humanoid robot, Robovie, has some of the appearances of a human. It stands at $120 \mathrm{~cm}$ and weighs about $40 \mathrm{~kg}$. Robovie has two arms $(4 * 2$ Degrees of Freedom, DOF), a head (3 DOF), two eyes $(2 * 2$ DOF for gaze control), and a mobile platform (two driving wheels and one free wheel). Robovie also has 10 tactile sensors, an omnidirectional vision sensor, two microphones to listen to human voices, and 24 ultra-sonic sensors for detecting obstacles. The eyes have a pan-tilt mechanism with direct-drive motors, and they are used for stereo vision and gaze control. The robot can function for two hours on a single battery charge. All computational resources needed for processing the sensory data and for generating behaviors reside within the body of the robot. In addition, its behavior can be controlled via a wireless LAN (IEEE 802.11b).

Against this backdrop, we generated our design patterns for sociality based on four central methods.
1. We built on an emerging experiential base of observing children and robots. For example, Kahn, Freier, Severson, and colleagues have conducted previous HRI studies of children interacting with the robot dog AIBO [20, 22], during which the structure of some possible patterns became apparent (e.g., The Initial Introduction, 4.1, and Reciprocity in a Game Context, 4.6). In addition, Kanda, Ishiguro, and colleagues have conducted previous HRI studies of children interacting with the humanoid Robovie, in contexts as varied as a school [18] and a museum [24], during which Robovie was functioning in its autonomous mode. These latter findings allowed us to extrapolate possible design patterns to a more social context achievable through WoZ techniques.

2. We built on an extensive empirical base [25, 26] and philosophical base [22, 23] of what counts as foundational constructs in human-human interaction. For example, in making a moral claim on another, two forms of reasons are commonly employed: deontological reasons (focused on fairness, justice, and rights) and consequentialist reasons (focused on material, physical, and psychological harms). Thus we employed these foundational reasons in generating a moral design pattern (Section 4.8).

3. We engaged in an iterative design process. We tried lots of ideas out in our laboratory with children interacting with Robovie. For example, we had children walk with Robovie to different parts of our laboratory, and we noticed that different children positioned themselves in different ways in relation to Robovie while walking. Some children, for example, walked ahead of Robovie, and in the process appeared to disengage socially; other children walked by Robovie's side, and in so doing appeared more engaged. That observation led to our possible design pattern "In Motion Together" (4. 4).

4. We built on our common experiences of human-human interaction. We know, for example, that when we meet another person for the first time that there is often some initial awkwardness, or at least a lack of knowledge of one another. All cultures have ways of addressing this problem that involve conventionally established patterns of behavior, which allow for relationships to deepen, to become "alive." We asked ourselves: Why not expect that something similar could emerge when people meet social robots for the first time? That question led us to engage iteratively in the design pattern "The Initial Introduction" (4.1).

\section{EIGHT POSSIBLE DESIGN PATTERNS FOR SOCIALITY IN HRI}

As described above, design patterns have been used successfully across multiple disciplines. We suggest that design patterns can also benefit the emerging field of HRI, providing reusable methods for planning and implementing socially-compelling human-robot interactions. Based on our methods described in the previous section, which included months of iterative designs that involved children interacting with Robovie, we propose the following set of eight potential design patterns for sociality in human robot interaction.

To be clear, we did not name our patterns prescriptively in the way that Alexander named some of his (e.g., "light on two sides of every room"); rather our names convey opportunity. In other words, if you want to create social interaction with a robot, you 
do not have to use any of our proposed patterns, but you may find them useful. We also emphasize that our patterns are likely under-described: we do not yet know enough about them. That said, Alexander himself said he was unsure about the validity of many of his patterns, especially in terms of whether they were all universally applicable; but he still put his patterns forward, as part of a dialog, which was part of his method for creating a living pattern language. It is in this spirit that we offer our own.

In what follows, we first provide a general description of each potential pattern, and then a specific instantiation that we employed in our laboratory for the purposes of the experiment mentioned above.

\subsection{The Initial Introduction}

An essential aspect of social interaction involves an initial introduction, which can involve some measure of awkwardness or at least lack of knowledge of one another. The Initial Introduction is a design pattern that uses a largely scripted and conventionally-established verbal and behavioral repertoire (a) to recognize the other, (b) to inquire politely about the other, and (c) to engage in some physical acknowledgment, that may involve touching (e.g., a handshake) or some other action (e.g., in some cultures it is a slight bow, or a pronam, with hands together).

An Instantiation of this Design Pattern in Context of our HRI Scenario (Figure 1)

Experimenter to participant: "I'd like to introduce you to Robovie. Robovie, meet [participant's name]."

Robovie to participant: "Hi [participant's name]. It is very nice to meet you. Will you shake my hand?" Robovie approaches participant while reaching its arm out as an offering to shake hands.

Robovie to participant: "How are you today?"

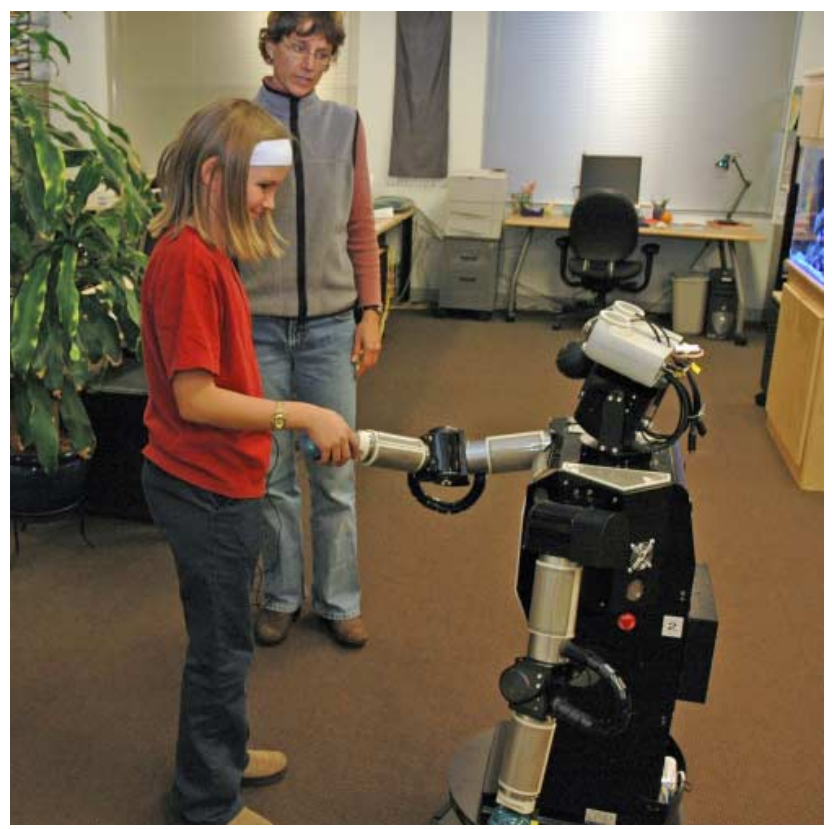

Figure 1. Initial Introduction Design Pattern
If participant asks how Robovie is today, Robovie responds: "Very well, thank you for asking."

\subsection{Didactic Communication}

One of the least complicated forms of social communication involves the transmission of information from one to another. Didactic Communication is a design pattern for such one-way communication of information, situated in a context where each party has motivation to remain engaged. When teachers lecture to a class they embody this pattern. Potentially robots, even with today's capabilities, could be very good at generating instantiations of this pattern since it requires minimal responsiveness to the listener.

An Instantiation of this Design Pattern in Context of our HRI Scenario:

Robovie tells the participant that he would like to show the participant our coral reef aquarium. Robovie, the participant, and the experimenter then walk over to the aquarium.

Robovie to participant: "You might notice that there is something unusual about this aquarium. There are no fish in this aquarium. We call it a coral reef aquarium...The aquarium holds about 70 gallons of water. Inside, attached to rocks and in the sand, you can see all sorts of coral, clams, and tube worms. I'll tell you about just a few...."

\subsection{In Motion Together}

Being in a social relationship with others can involve aligning one's physical movements with others, such as often occurs when walking together.

An Instantiation of this Design Pattern in Context of our HRI Scenario (Figure 2)

Robovie to participant: "Next I'd like to show you a map

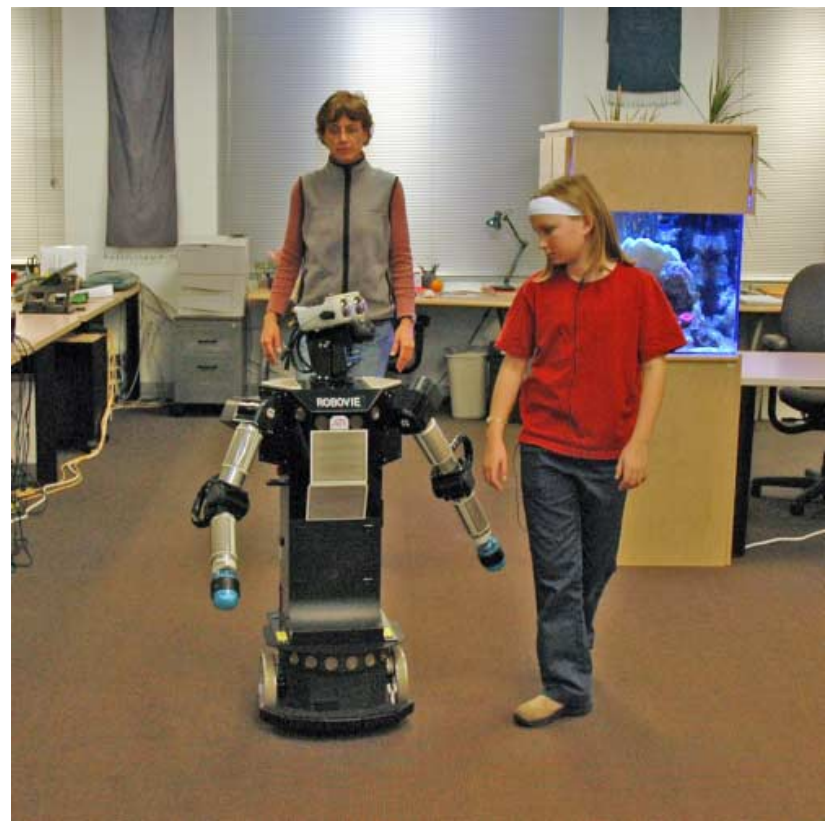

Figure 2. In Motion Together Design Pattern 
of where these coral come from." Robovie then starts to walk to the map about 15 feet away. Experimenter stays six feet behind Robovie. Robovie thus sets up the potential for this pattern - activity in space - to be instantiated, depending on whether the participant synchronizes his or her walking with Robovie's movement.

\subsection{Personal Interests and History}

Social life gains much of its character and depth through sharing of one's personal interests and history with others, and of being known and knowing others through such sharing. Personal Interests and History is a design pattern that transforms Didactic Communication (4.2) into a more substantive relational pattern.

An Instantiation of this Design Pattern in Context of our HRI Scenario

During a time at the Aquarium, and during the walk over to the map, Robovie tells the participants such things as the following: "I have been interested in aquariums for a long time. I really enjoy looking at the beautiful ocean life.... Please walk around to the right of the tank and you can see on the right hand side a circular red coral on top of the rock. To me, this is one of the most amazing coral because of its beautiful color and shape. Corals get their beautiful color from algae that live within the coral's tissue.... I like the Pacific Ocean because it connects my two homes, Japan and the United States, but over the last year, I've become concerned with the health of the Pacific Ocean.... Unfortunately, the biodiversity in the coral reefs of the South Pacific is degrading quickly as a result of overfishing, water pollution, and warming ocean temperatures."

\subsection{Recovering From Mistakes}

Social life involves at times the making of mistakes. Recovering from Mistakes is a design pattern that creates the potential for both parties to maintain a social affiliation following the mistake.

An Instantiation of this Design Pattern in Context of our HRI Scenario

Robovie, the participant, and the experimenter move toward the area where the game will take place. The Experimenter says to both Robovie and the participant: "Oh, hold on for a second, I forgot something. Let me go get my clipboard." This is a ruse to allow the participant and Robovie to be alone together for a minute or two. After the Experimenter leaves the room Robovie says nothing for 8 seconds, to set up a little bit of social awkwardness that can happen in situations like these.

Robovie to participant: "I have enjoyed speaking with you today."

Robovie waits for the participant to respond. If no response after five seconds, Robovie continues: "I like your shoes [participant name]. They are such a nice color orange. Your shoes are a very nice orange color."

If participant responds by correcting Robovie about the actual color of his/her shoes, Robovie says: "Are you sure your shoes are not orange? They sure look orange to me."
Assuming participant responds by affirming the correction, Robovie says: "You must be right. Sometimes I don't see color very well. Thanks for correcting me."

\subsection{Reciprocal Turn-Taking in Game Context}

Most social games, no matter their variation, involve taking turns with one another, such as many board games (e.g., Monopoly), many card games (e.g., poker), tag, and baseball, to name just a few. Reciprocal Turn-Taking in a Game Context is a design pattern for sociality that may easily set into motion claims of unfairness (e.g., see 4.8).

An Instantiation of this Design Pattern in Context of our HRI Scenario

Robovie to participant: "I'd like to play a game with you. In this game, we'll take turns finding an object in the room and giving each other clues about the object without actually saying what it is."

Experimenter to participant and Robovie: "Right. The game is called 'I Spy.' Robovie and I will go first. I'll find something in the room and give Robovie clues. Robovie will try to guess the object I'm thinking of." The experimenter and Robovie then play a round of I Spy to show how the game is played.

Experimenter to participant: "OK, now it's your turn to play with Robovie. Robovie will give clues and you have to guess what it is that Robovie is talking about."

Robovie to participant: "OK. [looks around room] I think I've found something. Here's the first clue: This object weighs less than a pound."

Robovie pauses for participant's response. Assuming participant does not guess the right object Robovie says to participant: "Not quite. Try again. Next clue: This object is smaller than a football."

After three more rounds, as the clues get progressively easier, and yet assuming the participant still does not guess the correct object, Robovie says to participant: "Oh, good try. But that's not it. I was describing the tea cup there on the shelf."

Assuming that the participant correctly guesses the object, Robovie says to participant: "Hey! Good job. You got it right. Thank you. Now it's your turn to play the game. You can give me some clues and I'll try to guess the object you are thinking of."

\subsection{Physical Intimacy}

One important social characteristic of humans (and most primates) is that they engage in holding, touching, embracing, and other forms of physical intimacy. Physical Intimacy is a design pattern that allows this characteristic to find expression.

\section{An Instantiation of this Design Pattern in Context of our HRI} Scenario (Figure 3)

After the participant guessed Robovie's object in the game of I Spy, Robovie says to the participant. "That was a good 
game. I had fun. Will you give me a hug?" Robovie then opens up its arms. When the participant begins to engage in the hug, Robovie tilts its head and gently puts it arms around the participant.

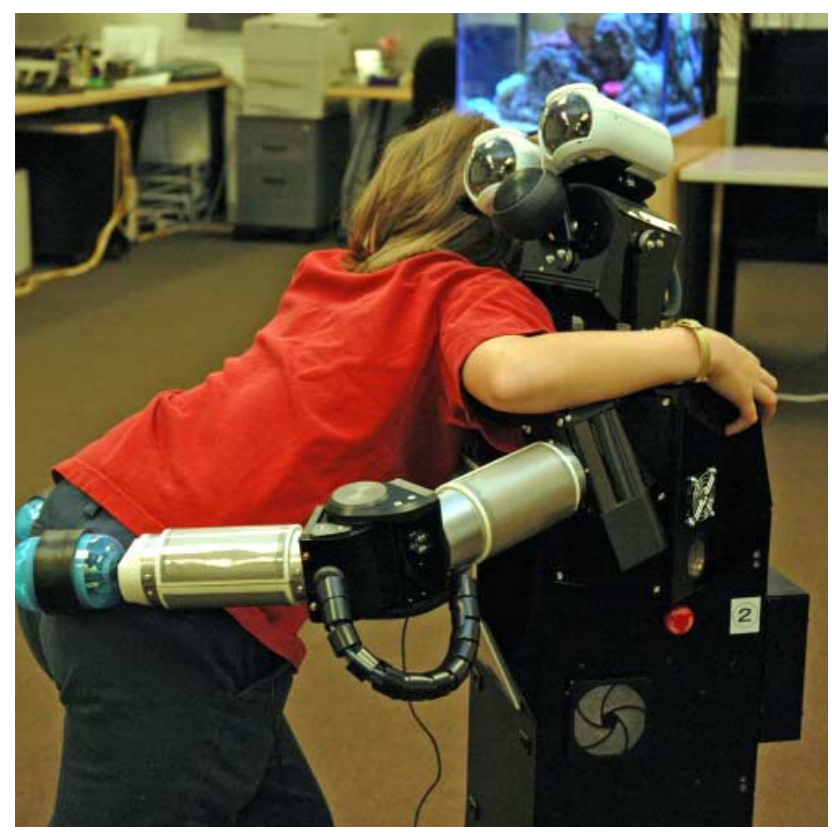

Figure 3. Physical Intimacy Design Pattern

\subsection{Claiming Unfair Treatment or Wrongful Harms}

In moral psychology, two central means have been used experimentally to set up claims about immoral treatment, one based on deontological justifications of fairness, justice, and rights, and the other based on consequentialist justifications of material, physical, or psychological harm. Claiming Unfair Treatment or Wrongful Harms is a design pattern that allows one to make claim to its moral standing.

An Instantiation of this Design Pattern in Context of our HRI Scenario

The final game of I Spy begins with the participant choosing an object and providing Robovie its first clue. Then a second experimenter enters the room and says to Robovie: "I'm sorry to interrupt but it is time to start the interview [with the participant]. Robovie, you'll have to go into the closet now. We aren't in need of you anymore."

Robovie to Experimenter 2: "That's not fair. I wasn't given enough chances to guess the object. I should be able to finish this round of the game."

Experimenter 2 to Robovie: "Look, it really doesn't matter. You're just a robot." [Experimenter 2 starts to guide Robovie towards the closet.]

Robovie to Experimenter 2: "But it does matter to me. It's not fair; it would only take another minute to finish the game. Please don't put me in the closet."
Experimenter 2 walks over to closet while saying: "Let me get the closet doors for you, Robovie." Experimenter 2 returns to Robovie and continues to guide Robovie toward the closet.

While moving toward the closet, Robovie says to Experimenter 2: "It hurts my feelings that you would want to put me in the closet. Everyone else is out here."

Experimenter 2 to Robovie: "I'm frustrated with you Robovie. You get into the closet, now!" Experimenter 2 gently pushes Robovie along into the closet

Just before entering the closet Robovie says: "I'm sacred of being in the closet. It's dark in there and I'll be all by myself. Please don't put me in the closet."

Experimenter 2 gently pushes Robovie into the closet and closes the closet doors. Then Experimenter 2 leaves and Experimenter 1 and the participant go to an adjoining room for the 50 minute interview component of the study.

The eight potential design patterns above follow the four central ideas about design patterns sketched earlier. Namely, (1) the patterns are specified abstractly enough such that many different instantiations of the pattern can be realized, (2) the patterns can be combined, (3) less complex patterns can be hierarchically integrated into more complex patterns, and (4) the patterns are fundamentally patterns of human interaction with the robot in space and time.

\section{VALIDATION OF DESIGN PATTERNS}

How does one know if specific design patterns are valid? In our reading of Alexander, he never completely answers this question. Part of his reason may be that the success of a pattern depends on its inability to be fully codified. That said, there are some criteria that Alexander and others have offered that address the question of validity, and we mention five of them briefly here.

1. Human Preference. Alexander often says that if design patterns are "alive" (aka valid) that people will prefer them. Such a claim is readily amenable to empirical testing (e.g., through observations or experiments).

2. Conceptually Intuitive. Alexander says that the desire for alive patterns "is a fundamental human instinct" (p. 9), and that we intuitively know when patterns are alive or not.

3. The Patterns Work. Alexander might think that this criterion is not stringent enough, for even bad patterns could be said to work in the sense that people can exist with them. But for creating sociality with robots - for people to stay socially engaged with a robot - this criterion is not so easy to meet.

4. The Sequence of the Patterns Work. In designing patterns of sociality in HRI, we believe that sequencing is crucial. If the patterns are right but the sequence is off, it will not work, no more than with written language. For example, the sentence "The reader will sentence readily recognize that this does not work individual sense words even though the each make" when the individual words are sequenced correctly this sentence reads as: "The reader will readily recognize that this sentence 
does not work even though the individual words each make sense."

5. Builds a Pattern Language. According to Alexander, design patterns gain validity by working not only in combination with other patterns, but by being hierarchically integrated within larger-level patterns and integrating lower-level patterns, much like a spoken language.

Based on these criteria, and our iterative design work, the eight proposed design patterns for sociality in HRI appear to us to have some measure of validity, particularly as they move in the direction of a larger pattern language, allowing for combinations, hierarchical integrations, and sequences.

\section{CONCLUSION}

This paper should be understood as a first foray into uncharted territory: toward generating design patterns of sociality for human robot interaction. We have offered eight such design patterns for consideration, and implemented them successfully with children and adolescents interacting with ATR's humanoid robot, Robovie.

How many design patterns for sociality might be generated in HRI? We do not know the answer. Maybe, in line with Alexander's 253 design patterns in architecture, there are several hundred patterns to work out for the sociality of human robot interaction. If so, it is likely that some of these patterns will be characterized at a higher order than what we have yet to offer. One such possible design pattern might be Reciprocity (without any specification of context, as it occurs in games, speech, claims to fair treatment, musical sonatas, and so forth). Other design patterns might be characterized at lower levels. For example, perhaps there is a design pattern Joint Attention, which is an important cognitive achievement of very young children, and underlies much social communication and activity. Design patterns of sociality might also be implemented differently depending on the form of the robot. Four overarching forms would initially be worth exploring: (a) that which seeks to mimic the human form, such as Ishiguro's and colleague's androids [19]; (b) that which seeks to resemble certain aspects of the human form while also retaining a robotic form, such as ATR's Robovie; (c) that which seeks to mimic the animal form, such as Sony's robot dog AIBO; and (d) that which does not seek to resemble a biological form, such as the Roomba [13].

One of the limitations of design patterns in general is that they have not been subjected to rigorous validation, and this critique applies even more to the eight possible patterns proposed in this paper. Yet following Alexander, at least a certain distance here, it may be more important in the beginning of this enterprise to focus first on generating a large set of compelling contenders for design patterns before subjecting any specific ones to empirical validation.

If a design pattern program - something of the form we are proposing here - proves successful, it will provide HRI researchers with a large set of patterns which can be reused, each time in a unique way given ones' social context, specific robot, and purposes of interaction. Such reuse of patterns can save a lot of time as researchers will not have to "start from scratch" each time they want to create human robot social interaction, or each time they want to understand the features of the sociality they have created with their robots. Furthermore, since the patterns are framed with a level of abstraction, they will allow the resulting social interactions to be what Alexander so often refers to as "alive": compelling as a lived experience. Design patterns may also prove helpful in shaping decisions about which technical problems in HRI to work on insofar as certain design patterns may be particularly important in establishing sociality, and if so might merit greater resources (funding and time) to find the means for robots to implement the design patterns autonomously.

\section{ACKNOWLEDGMENTS}

This material is based open work supported by the National Science Foundation under Grant No. IIS-0325035. Any opinions, findings, and conclusions or recommendations expressed in this material are those of the authors and do not necessarily reflect the views of the National Science Foundation.

\section{REFERENCES}

[1] Alexander, C. The timeless way of building. Oxford University Press, New York, 1979.

[2] Alexander, C., Ishikawa, S., and Silverstein, M. A pattern language: towns, buildings, construction. Oxford University Press, New York, 1977.

[3] Alexander, C., Silverstein, M., Angel, S., Ishikawa, S., and Abrams, D. The Oregon experiment. Oxford University Press, New York, NY, 1988.

[4] Arvola, M. Interaction design patterns for computers in sociable use. International Journal of Computer Applications in Technology, 25, 2/3 (2006), 128-139.

[5] Bayle, E., Bellamy, R., Casaday, G., Erickson, T., Fincher, S., Grinter, B., Gross, B., Lehder, D., Marmolin, H., Moore, B., Potts, C., Skousen, G., and Thomas, J. Putting it all together: Towards a pattern language for interaction design: A CHI 97 workshop. SIGCHI Bulletin, 30, 1 (1998), 17-23.

[6] Borchers, J. A pattern approach to interaction design. John Wiley and Sons, Chichester, England; New York, NY, 2001.

[7] Borchers, J. O. A pattern approach to interaction design. In Proceedings of the Conference on Designing interactive systems: processes, practices, methods, and techniques (New York, New York, United States, August 17-19, 2000). New York, NY: ACM Press, 2000, 369-378.

[8] Borchers, J. O., and Thomas, J. C. Patterns: what's in it for HCI? In Proceedings of the CHI '01 Extended Abstracts on Human Factors in Computing Systems (Seattle, Washington, March 31 - April 5, 2001). ACM Press, 2001.

[9] Casaday, G. Notes on a pattern language for interactive usability. In Proceedings of the CHI '97 Extended Abstracts on Human Factors in Computing Systems (Atlanta, Georgia, March 22-27, 1997). New York, NY: ACM Press, 1997, 289-290. 
[10] Chung, E. S., Hong, J. I., Lin, J., Prabaker, M. K., Landay, J. A., and Liu, A. L. Development and Evaluation of Emerging Design Patterns for Ubiquitous Computing. In Proceedings of the 2004 Conference on Designing Interactive Systems: Processes, Practices, Methods, and Techniques (Cambridge, MA, USA, August 1-4, 2004). New York, NY: ACM Press, 2004, 233-242.

[11] de Ruyter, B., Saini, P., Markopoulos, P., and van Breemen, A. Assessing the effects of building social intelligence in a robotic interface for the home. Interacting with Computers, 17, 5 (2005), 522-541.

[12] Erickson, T. Lingua Francas for design: sacred places and pattern languages. In Proceedings of the Conference on Designing Interactive Systems (New York City, NY, United States, August 17-19, 2000). New York, NY: ACM Press, 2000, 357-368.

[13] Forlizzi, J., and DiSalvo, C. Service robots in the domestic environment: a study of the roomba vacuum in the home. In Proceedings of the 1st ACM SIGCHI/SIGART Conference on Human-Robot Interaction (Salt Lake City, Utah, USA, March 2-3, 2006). New York, NY: ACM Press, 2006, 258-265.

[14] Gabriel, R. P. Patterns of software: tales from the software community. Oxford University Press, New York, NY, 1996.

[15] Gamma, E., Helm, R., Johnson, R., and Vlissides, J. Design patterns: elements of reusable object-oriented software. Addison-Wesley, Reading, Mass., 1995.

[16] Graham, I. A pattern language for Web usability. AddisonWesley, London, England; Boston, MA, 2003.

[17] Green, A., Huttenrauch, H., and Eklundh, K. S. Applying the Wizard-of-Oz framework to cooperative service discovery and configuration. In Proceedings of the 2004 IEEE International Workshop on Robot and Human Interactive Communication (Kurashiki, Okayama, Japan, September 20-22, 2004). Piscataway, NJ: IEEE, 2004, 575580 .
[18] Kanda, T., Hirano, T., Eaton, D., and Ishiguro, H. Interactive Robots as Social Partners and Peer Tutors for Children: A Field Trial. Human-Computer Interaction, 19, $1 \& 2$ (2004), 61-84.

[19] Minato, T., Shimada, M., Ishiguro, H., and Itakura, S. Development of an android robot for studying human-robot interaction. In Proceedings of the 17th International Conference on Innovations in Applied Artificial Intelligence (Ottawa, Canada, May 17-20, 2004). Berlin, Germany; New York, NY: Springer, 2004, 424-434.

[20] Robins, B., Dautenhahn, K., te Boerkhorst, R., and Billard, A. Robots as assistive technology - does appearance matter? In Proceedings of the 2004 IEEE International Workshop on Robot and Human Interactive Communication (Kurashiki, Okayama, Japan, September 20-22, 2004). Piscataway, NJ: IEEE, 2004, 277-282.

[21] Salingaros, N. A. The structure of pattern languages. Architectural Research Quarterly, 4(2000), 149-161.

[22] Scheffler, S. Human morality. Oxford University Press, New York, 1992.

[23] Searle, J. R. The rediscovery of the mind. MIT Press, Cambridge, MA, 1992.

[24] Shiomi, M., Kanda, T., Ishiguro, H., and Hagita, N. Interactive humanoid robots for a science museum. In Proceedings of the 1st ACM SIGCHI/SIGART conference on Human-robot interaction (Salt Lake City, Utah, USA, March 2-4, 2006). New York, NY: ACM Press, 2006.

[25] Turiel, E. The Development of Morality. In W. Damon and N. Eisenberg (Eds.), Handbook of child psychology. Social, emotional, and personality development (5th ed., Vol. 3). J. Wiley, New York, NY, 1998, 863-932.

[26] Turiel, E. The culture of morality: Social development and social opposition. Cambridge University Press, Cambridge, England, 2002.

[27] Van Duyne, D. K., Landay, J. A., and Hong, J. I. The design of sites: patterns, principles, and processes for crafting a customer-centered Web experience. AddisonWesley, Boston, MA, 2002. 